\title{
The App Save Yourself Improves Knowledge in Earth Environmental Emergency and Safe Behaviors
}

\author{
Sabina Maraffi, Dr. \\ University of Camerino, Camerino, Italy \\ Francesco M. Sacerdoti, Prof. \\ e-voluzione srl, Naples, Italy
}

Doi: 10.19044/esj.2018.c5p1

URL:http://dx.doi.org/10.19044/esj.2018.c5p1

\begin{abstract}
Saving Yourself is an App from the methodological experience of Learning on Gaming, which is a new teaching approach: to learn while playing, that is different from Edutainment, designed both to educate and entertain, and Gaming to Learn, which consists of playing a game without specific didactic to outcome knowledge. With Learning on Gaming the game "hides" didactic inside the game: this could improve learning processes and, at the same time, renew teaching competences of mentors. Our experience is based on the application of Learning on Gaming to Digital Game Based Learning, through a Computer Class Role Playing Game (CCRPG).

Adventure pathways of these CCRPG are focused on Earth Sciences and are interdisciplinary, multilingual and they are a good example of innovative teaching. As a CCRPG spin-off, "Saving Yourselves" is an App for Educators, Trainers, Teachers, Students, to know the earthquakes and volcanoes and strategies to reduce the risks associated with these phenomena.

The App is intended to provide the most immediate and useful way to behave in the event of a geological emergency, with particular reference to volcanology emergency and seismic emergency. It can be used at school to optimize security education measures, but it can also be a game that is useful to rethink what has been learned.

Saving Yourself is for all ages, because there are versions of the activity for kindergarten, primary school and secondary school and it is multilingual. It takes advantage of Games, ICT (Information and Communication Technologies), Innovative Teaching, to activate digital, scientific and technical skills.
\end{abstract}

Keywords: App, Education, Gaming, Safety, Emergency 


\section{Introduction}

An innovative teaching technology combines ICT, traditional and modern media, and social networks, where gaming is a key element. (Maraffi, S., Paris, E. \& Sacerdoti, F. M., 2017). Chapman and Rich (2017) claimed that games might encourage students to spend more time studying, be more engaged, and as a result, learn more. This new way of learning offers new opportunities to use collaborative tools, allowing the students to co-construct knowledge efficiently (González-González, Collazos, Guerrero, \& Moreno, 2016).

Educational technologies that use more suitable tools to students improve the teaching-learning process; games and video games are excellent educational vehicles, so we have developed and successfully experimented a Computer Class Role Playing Game (CCRPG): GeoQuest Project (Maraffi, S., Paris, E. \& Sacerdoti, F. M., 2017). Adventure pathways of these CCRPG are focused on Earth Sciences and are interdisciplinary, multilingual and they are a good example of innovative teaching.

From the methodological experience of Learning on Gaming, derives an App to improve Earth's Sciences, particularly Geophysics, and above all to improve environmental and safety education (Fig. 1).
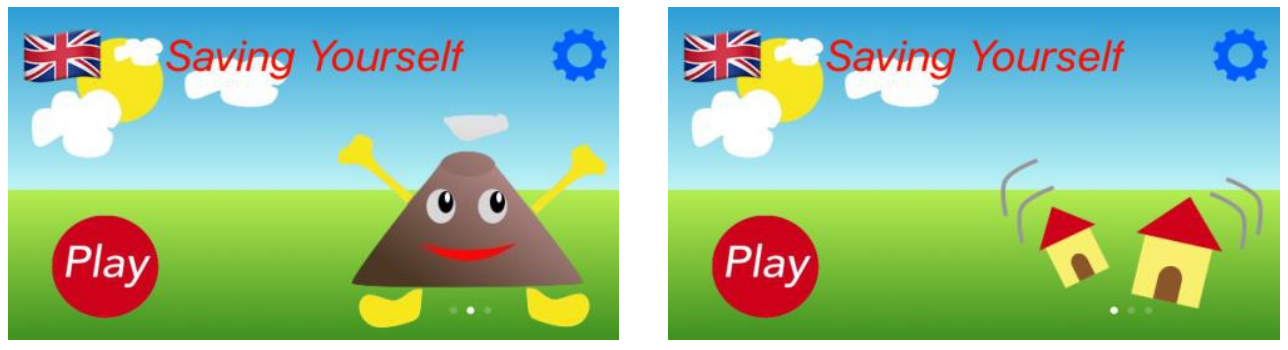

Figure 1. Saving Yourself versions for volcanological and seismological emergency.

\section{Methodology}

Saving Yourself is an App on iOS (https://itunes.apple.com/it/app/sisalvi-chi-pu\%C3\%B2/id1251674281?mt=8) to learn the correct behaviors in Earth Environmental Emergency. The App is intended to provide, in the most immediate and practicable way, what are the correct behaviors in the event of geological emergencies, with particular reference to volcanological and seismic emergency. The adventures has been built for different ages; they can be used at school to optimize education safety measures, but can also be useful to refresh what has been studied.

Methodology is storytelling, gaming (Fig. 2), use of information and communication technologies, innovative teaching. For the youngest we can use storytelling to bring kids through our comics. Through the myth, for 
example, we talk about Volcanological emergency of Vesuvius and we exploit the mythology of Homeros or Virgil's poems.

All Saving yourself apps are enriched with original designs, suitable for the

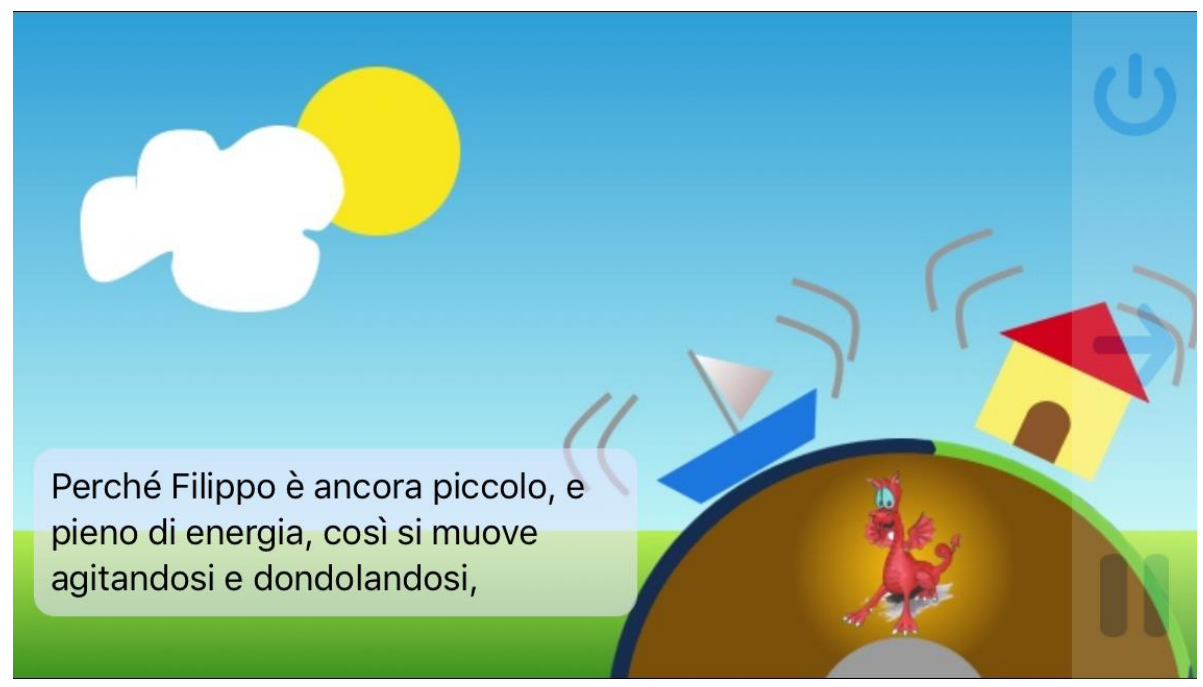

Figure 2. Methodology is storytelling, gaming, use of information and communication technologies, innovative teaching.

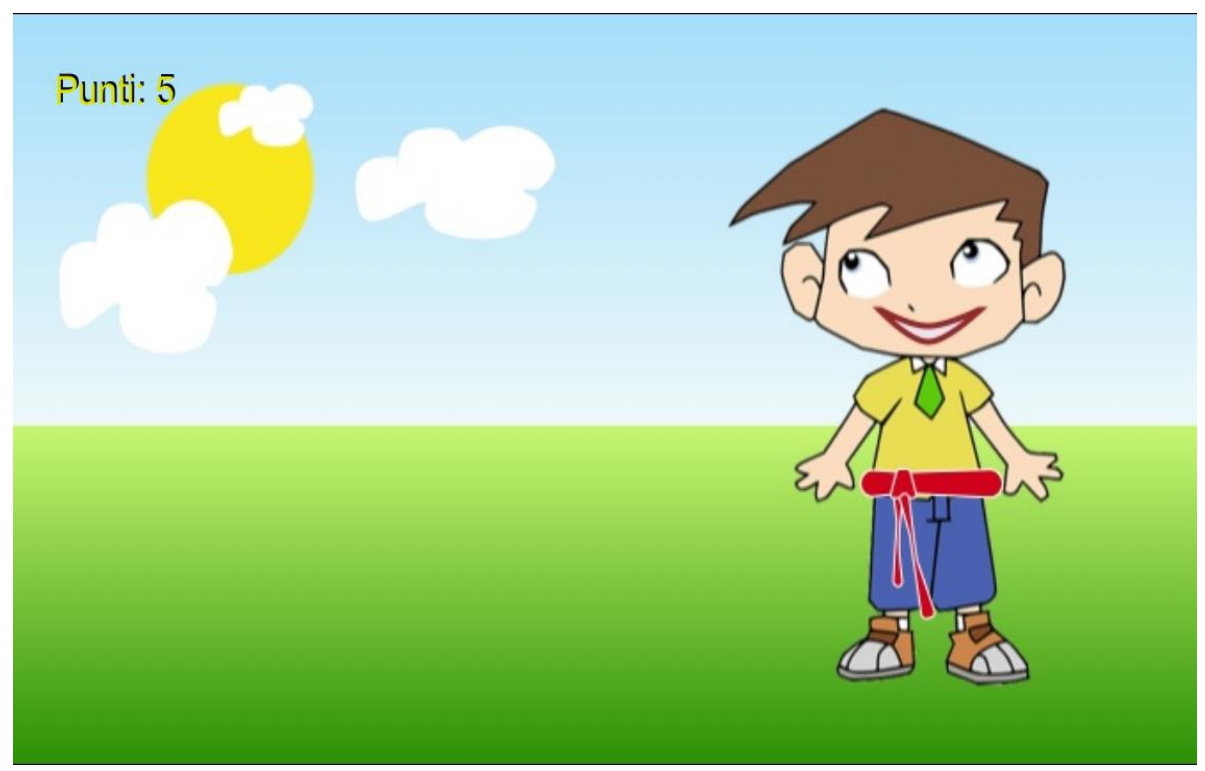

Figure 3. Another engage element is multiple game levels, with different prizes: a green belt, a red belt, a blue belt, a safety star. 
youngest, and nice for all ages. Another engage element is multiple game levels, with different prizes: a green belt, a red belt (Fig. 3), a blue belt, a safety star and so on. At the end of the game, each player can do a test to check what kind of "emergency expert" he or she has become.

Another important point of strength is immediate feedback (Fig. 4): wrong answer is indicated in red, while the correct answer appears in green. Then follows some explanation on the right answer. Through the App and the game, a wealth of valuable information is provided; for example, the rise of the gas inside the magma, or terms such as vulnerability, danger, and risk.

With GIFs, the geophysical mechanisms are clarified (Fig. 5), so it is easier to defeat frequent misunderstandings. In particular earthquake version aims to get aware and responsible informations, to avoid panic, to keep a healthy caution.

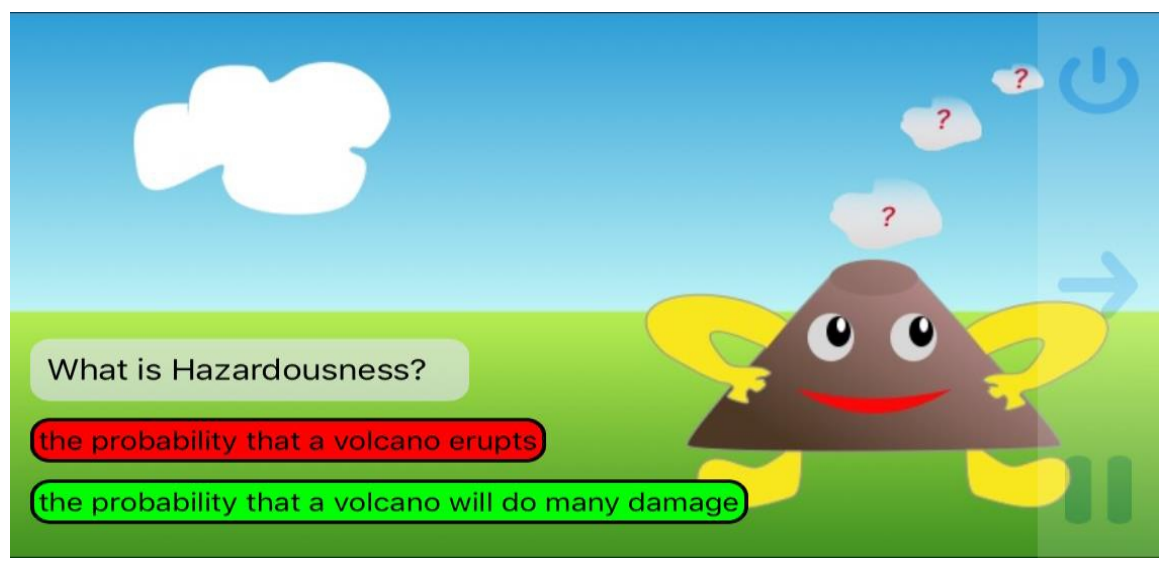

Figure 4. Immediate feedback: wrong answer is indicated in red, while the correct answer appears in green.

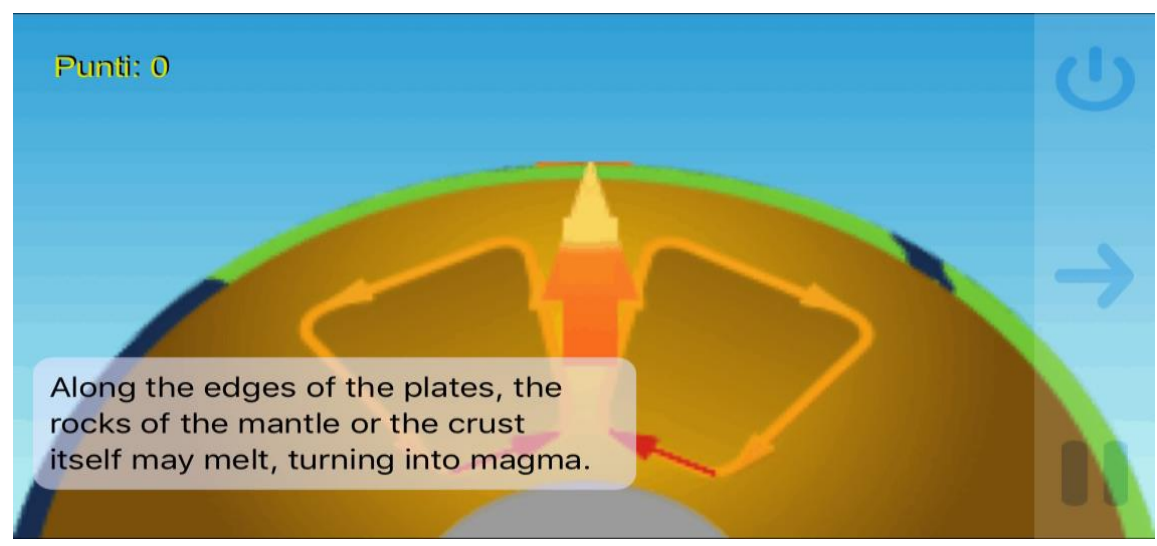

Figure 5. With GIFs, the geophvsical mechanisms are clarified. 


\section{Conclusion:}

Apps are today the best vehicle to meet the interest of young people (Maraffi, S. \& Sacerdoti, F.M., 2017). Saving Yourself is freely downloadable and available for everyone. The dynamics of levels and prizes pushes the player to move forward and at the same time to acquire the necessary knowledge and skills.

The final test certainly helps to give the player the awareness of the degree of learning achieved, but can also serve to push to repeat the experience to improve their results. We know, in fact, that the self-test proposal is an element of strong appeal, which is often used in publicity and communication.

All this improves to the experience of Learning on Gaming, which we have recently experimented extensively with more than satisfactory results (Maraffi, S. \& Sacerdoti, F.M., 2018).

\section{References:}

1. Chapman, J. R., \& Rich, P. Identifying motivational styles in educational gamification. In Proceedings of the 50th Hawaii International Conference on System Sciences, Hawaii, USA. 2017.

2. González-González, C. S., Collazos, C. A., Guerrero, L. A., \& Moreno, L. Game-based learning environments: Designing the collaborative learning processes. Acta Scientiae, 18(4), 12-28. 2016.

3. Maraffi, S., Paris, E. \& Sacerdoti, F. M. Learning on Gaming: A New Digital Game Based Learning Approach to Improve Education Outcomes. US-China Education Review A, September 2017, Vol. 7, No. 9, 421-432. doi: 10.17265/2161-623X/2017.09.003. http://www.davidpublisher.org/Public/uploads/Contribute/5a38cc913 519c.pdf. 2017.

4. Maraffi, S. \& Sacerdoti, F.M. "Save Yourselves": an App to Improve Correct Behaviors in Earth Environmental Emergency. American Geophysical Union Fall Meeting, New Orleans, USA. 2017.

5. Maraffi, S. \& Sacerdoti, F.M. GeoQuest Project. Implementation and experimentation of a Computer Classroom Role Playing Game: final results. In publication. 